\title{
Patients' Preferences on Information and Involvement in Decision Making for Gastrointestinal Surgery
}

\author{
Emilie Uldry • Markus Schäfer • Alend Saadi • \\ Valentin Rousson • Nicolas Demartines
}

Published online: 15 May 2013

(C) Société Internationale de Chirurgie 2013

\begin{abstract}
Background The relationship between physicians and patients has undergone important changes, and the current emancipation of patients has led to a real partnership in medical decision making. The present study aimed to assess patients' preferences on different aspects of decision making during treatment and potential complications, as well as the amount and type of preoperative information wanted before visceral surgery.

Methods This was a prospective non-randomized study based on a questionnaire given to 253 consecutive patients scheduled for elective gastrointestinal surgery.

Results In considering surgical complications or treatment in the intensive care unit, $64 \%$ of patients wished to take an active role in any medical decisions. The respective figures for cardiac resuscitation and treatment limitations were 89 and $60 \%$. As for information, 73, 77, and $47 \%$ of patients wish detailed information, information on a potential ICU hospitalization, and knowledge of cardiac resuscitation, respectively. Elderly and low-educated patients were significantly less interested in shared medical decision making ( $p=0.003$ and 0.015$)$, and in receiving information ( $p=0.03$ and 0.05). Similarly, involvement of the family in decision making was significantly less important to elderly and male patients $(p=0.05$ and 0.03 ,
\end{abstract}

E. Uldry $(\bowtie) \cdot$ M. Schäfer · A. Saadi · N. Demartines Department of Visceral Surgery, University Hospital of Lausanne (CHUV), 1011 Lausanne, Switzerland e-mail: Emilie.Uldry@chuv.ch

N. Demartines

e-mail: demartines@chuv.ch

V. Rousson

Statistical Unit, Institute for Social and Preventive Medicine,

University Hospital of Lausanne, 1011 Lausanne, Switzerland respectively). Neither the type of operation (minor or major) nor the severity of disease (malignancies versus non-malignancies) was a significant factor for shared decision making, information, or family involvement.

Conclusions The vast majority of surgical patients clearly want to get adequate preoperative information about their disease and the planned treatment. They also consider it crucial to be involved in any kind of decision making for treatment and complications. For most patients, the family role is limited to supporting the treating physicians if the patient is unable to participate in decision making.

\section{Introduction}

The relationship between physicians and patients has undergone manifold changes during recent decades. These alterations have been particularly fostered by the rapid development of modern medicine and the overwhelming availability of medical information provided by the Internet and other electronic media. Public debates concerning delicate topics such as medicide, abortion, and genetic testing for disabling and lethal diseases have contributed to the emancipation of patients. Nowadays, patients are rather considered as clients having their own opinions that warrant them to become real partners. The bygone era when patients accepted all verdicts made by their doctors, definitively belong to the past. But it also has to be kept in mind that modern medicine has rapidly become complex, and its specialization causes a significant fragmentation of medicine. Patients are increasingly confronted with many doctors representing different specialties and sophisticated treatment modalities. More clinical situations are emerging where difficult decisions 
associated with major consequences have to be taken. Therefore, patients urgently need loyal and faithful physicians to guide them safely through.

All these changes have gained increased attention within the medical community and have led to the promotion of research in patient preferences for information and decisional roles in the treatment process [1]. In order to properly involve patients in decisions about their own health, a shift toward a distinct patient-oriented approach has been observed [2-4]. In fact, the term "shared decision making" (SDM) has been coined [5, 6] to describe physicians' and patient's common decision making based on the best available evidence, and includes the patient's right to be informed in a proper way on health status, the examinations performed, possible treatments, and the inherent consequences and risks [7-9]. There is good evidence that the SDM approach, by promoting patient engagement and respecting patient autonomy, results in a variety of benefits, including improved patient satisfaction and clinical outcomes [10-14]. Hence, patient-oriented communication and SDM must be considered key concepts in defining a modern relationship between doctors and their patients $[15,16]$.

Preferences have been explored in cancer patients, but specific data for surgical patients are nonexistent. Our prospective study aimed to assess patient preferences on perioperative information and decision making with regard to serious postoperative complications, intensive care unit hospitalization, or cardiac resuscitation for patients undergoing elective operations for different types of gastrointestinal (GI) diseases.

\section{Methods}

\section{Study design}

The study was an observational trial that used a crosssectional design and was performed at the Department of Visceral Surgery, University Hospital of Lausanne, Switzerland. We assessed patient preferences on the amount and type of preoperative information, as well as different aspects of decision making during treatment. To this end, patients were primarily divided into two main groups-those undergoing minor surgery and those requiring major surgery. Those two groups were stratified regarding age in a continuous way and regarding gender. A further splitting of the major surgery group into two subgroups, namely major non-oncological surgery and major oncological surgery, was then carried out. The patients' educational levels and gender were separately assessed and used as the discriminating factors for final analysis.
The study protocol was approved by the local ethics committee, and informed consent was received prior to enrolment from all patients.

Patients and settings

Between November 2008 and June 2010 all patients scheduled for elective GI surgery at our institution were asked to participate in the study. Thus, only patients fulfilling inclusion criteria concerning the type of operation were considered eligible. Minor surgery included the following operations: laparoscopic cholecystectomy and laparoscopic colon resection for benign disease (mostly diverticular disease). Major surgery included esophagectomy, hepatectomy, gastrectomy, extended colonic resections, proctectomy, and retroperitoneal sarcoma resection for benign, malignant, and metastasized disease.

The patients' level of education was stratified as no or low education, average education, and superior education. No or low education was defined as obligatory school level without additional formation (e.g., bricklayer, farmer...), whereas average education meant obligatory school and a maximum 4 years of postgraduate formation (e.g., teacher, nurse...). Finally, superior education included academic training or more than 4 years of postgraduate formation (e.g., engineer, lawyer...). For retired patients ( $>65$ years of age in Switzerland), it was not always possible to define the level of education.

Patient age was stratified in a continuous way, and we calculated an odds ratio-i.e., a mean difference-indicating what was expected for an increase of 10 years. Patients more than 65 years of age were classified as "old."

Exclusion criteria were age $<18$ years, emergency procedures, impaired understanding of the French language, and absence of informed consent.

\section{Implementation}

Patients were asked to participate during their preadmission consultation at the outpatient department by the operating surgeon. This noninvasive patient-centered study had a wide and easy acceptance. Enrollment and allocation concealment were then performed by a study nurse so that no patient was lost. Patients completed the questionnaire at home, and the study nurse collected each one at the time of hospital admission for the planned operation. If the questionnaire was not completed, the study nurse always asked the patients to provide any missing information and, if necessary, helped them complete the questionnaire. All answers were extracted and documented anonymously by two co-authors (E.U., A.S.) in a database developed a priori for the current study. All patients received similar 
preoperative information concerning the planned surgery and its potential classical postoperative complications, defined as complications occurring more frequently than $5 \%$ of the time (e.g., surgical site infection post colorectal surgery) or specific to the type of surgery even if $<5 \%$ (e.g., main bile duct injury in case of cholecystectomy). At the end of the consultation, patients signed an informed consent as usual.

\section{Questionnaire and outcomes parameters}

Despite a careful review of the literature, we could not identify a suitable questionnaire covering the specific requirements of this study [17-19]. Therefore, we developed a simple questionnaire and, knowing that validation could not have been done, we sought the assistance of a psychiatrist specialized in doctor-patient relationships. The questionnaire included 13 binary questions (each with two possible answers $1=$ yes $/ 0=$ no) (Table 1 ). To make it possible to summarize the information, several questions were grouped together, based on the observed correlations of the answers, as well as on some a priori knowledge. At the end, three scores were defined. The first score (score 1) summarizes the answers of four questions regarding the patient's requirement for type and extent of information (ranging from a value of 0 for a patient to whom getting information does not seem to be important, to a value of 4 for a patient to whom information is very important). The second score (score 2) summarizes the answers of seven questions on patient participation in decision making (ranging from 0 for a patient who does not wish to be involved at all, to a value of 7 for a patient who wishes to be maximally involved). The third score (score 3 ) is a sum of the answers to four questions covering family involvement in decision making (ranging from 0 for a patient who does not wish his/her family to get involved at all, to a value of 4 for a patient who wants his/her family to be maximally involved). We focused our analysis on these three scores, but we also presented the results of single questions if they were considered to provide more information and more details.

\section{Statistics}

The sample size calculation was based on $80 \%$ power, $\alpha=0.05$, based on the hypothesis that the number of patients planned for major surgery and wishing to participate to medical decisions was $10 \pm 5 \%$ higher than the number of patients in the minor surgery group. To achieve this level of power, 87 patients should be included in each surgery group (major oncological surgery, major non-oncological surgery, and minor surgery).
Each binary question and each score were analyzed globally, as well as in relation to the factors of interest (gender, education, type of operation). Binary outcomes were summarized as proportions, and scores were calculated as averages (together with $95 \%$ confidence intervals). Comparison of proportions among different groups (e.g., men and women) was assessed with $\chi^{2}$ tests, and comparison of averages was obtained with analysis of variance (ANOVA). For the continuous factor age, we calculated an odds ratio-i.e., a mean difference-indicating what is expected for an increase of 10 years. In the multivariate analysis that included simultaneously the four factors of interest as explanatory variables, we used logistic regression to analyze the binary outcomes and linear regression to analyze the scores. Again, results were expressed as odds ratios for the former, and as mean differences for the latter; $p$ values $>0.05$ were considered significant.

\section{Results}

A total number of 254 patients were eligible for our study, and $253(99.6 \%)$ completed the questionnaire. Patient characteristics and results are summarized in Tables 2 and 3. The four factors of interest (gender, age, educational level, and type of operation) were, however, not independent of one another, as shown by the multivariate analyses. For example, men were older than women (mean age 60.4 years versus 55.9 years; $p=0.024$ ) and were more educated than women $(21.6 \%$ of men among patients with no education, $48.8 \%$ among the patients with an average education, and $76.9 \%$ among the most educated; $p<0.001$ ). Unlike low response rates reported in the literature (often below $50 \%$ ), we had a response rate of $99.6 \%$ because all patients but one agreed to participate. Because missing data were carefully collected by the study nurse, very few data points on individual questionnaires were lacking; in fact, only 5 answers on all questionnaires were left blank.

\section{Information}

Table 4 presents the results derived from questions on the amount of information wanted by the patients. Thus, $72.7 \%$ of the patients wished detailed information preoperatively (Q1), $31.6 \%$ wished to be informed on all potential complications related to treatment (Q2), $76.7 \%$ found it important prior to an operative intervention to have the opportunity to discuss the possible need for ICU admission (Q3), and $47.0 \%$ found it essential to discuss what should be done in case of a cardiac arrest, which represents the worst case scenario during the postoperative 
Table 1 Details of the binary questions used for the definition of the three summarizing scores

\begin{tabular}{|c|c|}
\hline Q1 & About the operation you are undergoing, which amount of information do you need: $1=$ detailed; $0=$ brief or none \\
\hline Q2 & Considering potential surgical complications, you want to know: $1=$ all; $0=$ some \\
\hline Q3 & Talking about a possible stay in the ICU is: $1=$ important; $0=$ not important \\
\hline Q4 & Talking about what to do in case of cardiac arrest (worst case scenario) is: $1=$ essential; $0=$ not essential \\
\hline Q5 & $\begin{array}{l}\text { If a new reoperation is warranted because of complications, you would like to: } 1 \text { = participate to medical decisions; } \\
0=\text { just follow what your doctor decided }\end{array}$ \\
\hline Q6 & If an unexpected stay in the ICU is needed, the decision should be taken by: $1=$ you and your doctor; $0=$ your doctor alone \\
\hline Q7 & $\begin{array}{l}\text { If you are conscious, you would like to share the discussion about what to do in case of cardiac arrest (worst case scenario): } \\
1=\text { yes; } 0=\text { no }\end{array}$ \\
\hline Q8 & According to you, who should start talking about it $(\mathrm{Q} 7): 1=$ patient; $0=$ doctor \\
\hline Q9 & $\begin{array}{l}\text { If you suffer from cancer or in palliative situation, talking about any therapeutic limits of the treatment is: } 1=\text { essential; } \\
0=\text { not essential }\end{array}$ \\
\hline Q10 & If your medical situation is worsening, would you like it to be discussed with your relatives? $1=$ yes; $0=$ no \\
\hline Q11 & $\begin{array}{l}\text { If you are unable to give your opinion or unconscious, you would like doctors to speak with your relatives to decide } \\
\text { the best option for you: } 1=\text { yes; } 0=\text { no }\end{array}$ \\
\hline Q12 & If you are conscious, would you like your relatives to take part in the decision of a cardiac resuscitation: $1=$ yes; $0=$ no \\
\hline Q13 & $\begin{array}{l}\text { If unconscious, would you like your relatives to take part in the decision of a cardiac resuscitation (worst case scenario): } \\
1=\text { yes; } 0=\text { no }\end{array}$ \\
\hline SCORE 1 & $\mathrm{Q} 1+\mathrm{Q} 2+\mathrm{Q} 3+\mathrm{Q} 4$ (score information) \\
\hline SCORE 2 & $\mathrm{Q} 3+\mathrm{Q} 4+\mathrm{Q} 5+\mathrm{Q} 6+\mathrm{Q} 7+\mathrm{Q} 8+\mathrm{Q} 9$ (score postoperative decision making) \\
\hline SCORE 3 & $\mathrm{Q} 10+\mathrm{Q} 11+\mathrm{Q} 12+\mathrm{Q} 13$ (score family) \\
\hline
\end{tabular}

ICU intensive care unit

Table 2 Patients' general characteristics

\begin{tabular}{ll}
\hline Parameters & \\
\hline Gender (male/female) (\%) & $133 / 120(52.6 / 47.4)$ \\
Age, years & $58.3 \pm 15.5$ \\
Education, $n(\%)$ & $37(14.6)$ \\
None or low & $80(31.6)$ \\
Average & $39(15.4)$ \\
Superior & $97(38.3)$ \\
Retired & \\
Type of surgery, $n(\%)$ & $108(42.7)$ \\
Minor & $34(13.4)$ \\
Major non-oncological & $111(43.9)$ \\
Major oncological &
\end{tabular}

course (Q4). Only slightly more than half of all patients $(51.8 \%)$ preferred written information to oral information. Patients with a low level of education or undergoing minor surgery were statistically significantly less interested in written information.

We calculated the "information" score (score 1) summing up four questions concerning this topic. In this score, men had a (nonsignificant) tendency to want less information than women (average score 2.17 vs. 2.41; $p=0.11$ ), as were patients with a low level of education or with a superior education, compared to those with an average education (average score: 2.24 and 2.08, vs. 2.59; $p=0.059)$. The main finding was that older patients sought significantly less information than younger patients (on average -0.10 points with respect to the score every 10 years; $p=0.038$ ), this tendency being confirmed in the multivariate analysis $(-0.13$ points every 10 years; $p=0.021)$.

\section{Decision making}

Table 5 contains the results about questions on the patient's role in medical decision making during the postoperative course. Thus, $63.6 \%$ of all patients would like to actively participate in the medical decision making if a secondary operation becomes mandatory to treat complications (Q5), and $61.3 \%$ in case a future ICU stay becomes necessary (Q6). Elderly patients were significantly more often in favor of delegating these two decisions to their treating physicians $(p=0.03)$, whereas women in general considered it significantly less important to be involved in decision making for the specific topic of a further operation $(p=0.04)$.

As long as patients are conscious and thus able to participate, $88.9 \%$ of all patients want to be involved in the decision making about whether resuscitation should be 
Table 3 Results

\begin{tabular}{|c|c|c|c|}
\hline Parameters & $\begin{array}{l}\text { Score information (1): } \\
\text { "less information needed" }\end{array}$ & $\begin{array}{l}\text { Score SDM (2): "no } \\
\text { involvement in SDM" }\end{array}$ & $\begin{array}{l}\text { Score family(3): "no } \\
\text { involvement of family" }\end{array}$ \\
\hline \multicolumn{4}{|l|}{ Gender } \\
\hline Male & Tendency $(p=0.11)$ & Ns & $p=0.03$ \\
\hline Female & Ns & & Ns \\
\hline \multicolumn{4}{|l|}{ Age } \\
\hline \multicolumn{4}{|l|}{ Continuous (by decade) } \\
\hline Older versus younger & $p=0.002$ & $p=0.03$ & $p=0.03$ \\
\hline \multicolumn{4}{|l|}{ Education level } \\
\hline None or low & Tendency $(p=0.06)$ & $p=0.02$ & Ns \\
\hline Average & Tendency $(p=0.06)$ & Ns & \\
\hline Superior & Ns & $p=0.02$ & \\
\hline Retired & Ns & Ns & \\
\hline \multicolumn{4}{|l|}{ Type of diagnosis/surgery } \\
\hline Minor & Ns & Ns & Ns \\
\hline \multicolumn{4}{|l|}{ Major non-oncological } \\
\hline Major oncological & & & \\
\hline
\end{tabular}

$S D M$ shared decision making

performed in case of postoperative cardiac arrest (Q7). But only $10.7 \%$ advocated that such a discussion should be initiated by the patient (Q8). In the particular case of cancer treatment, $59.9 \%$ of all patients judged it essential to discuss possible therapeutic limitations if severe, lifethreatening complications were to occur. This involved resuscitation after cardiac arrest and reoperation and retransfer to the ICU with its adjacent maximized therapies (Q9). More detailed information on the significance of the four factors of interest is shown in Table 5.

In the score for "postoperative decision making," summing up the five questions (score 2), patients with no education or with a superior education had less desire to be involved in the medical decision than those with an average educational level (average score 4.11 and 3.82 vs. 4.62; $p=0.015$ ), a tendency that was confirmed in the multivariate analysis, although no longer significantly $(p=0.13)$. This desire was also significantly lower among older patients than younger patients (on average -0.20 points every 10 years; $p=0.003$ ), again, the tendency that was confirmed in the multivariate analysis $(-0.23$ points every 10 years; $p=0.002$ ). Among the different types of operation, a higher score was achieved for patients with a major non-oncological operation (4.59 vs. 4.17 and 3.89 for those

Table 4 Analysis of the score information (score 1), and the binary questions involved

\begin{tabular}{|c|c|c|c|c|c|}
\hline & Q1 & Q2 & Q3 & Q4 & $\begin{array}{l}\text { Score } \\
\text { information }^{\mathrm{a}}\end{array}$ \\
\hline Sample size & $n=253$ & $n=253$ & $n=253$ & $n=253$ & $n=253$ \\
\hline Results (\%) & $72.7 \%$ & $31.6 \%$ & $76.7 \%$ & $47.0 \%$ & 2.28 \\
\hline$(95 \% \mathrm{CI})$ & $(66.9 \%-77.8 \%)$ & $(26.2 \%-37.6 \%)$ & $(71.1 \%-81.5 \%)$ & $(41.0 \%-53.2 \%)$ & $(2.13-2.43)$ \\
\hline \multicolumn{6}{|l|}{ Univariate analysis } \\
\hline Gender & $p=0.83$ & $p=0.041$ & $p=0.18$ & $p=0.44$ & $p=0.11$ \\
\hline Education & $p=0.34$ & $p=0.45$ & $p=0.039$ & $p=0.14$ & $p=0.059$ \\
\hline Type of operation & $p=0.29$ & $p=0.19$ & $p=0.42$ & $p=0.89$ & $p=0.29$ \\
\hline Age & $p=0.043$ & $p=0.040$ & $p=0.26$ & $p=0.72$ & $p=0.038$ \\
\hline \multicolumn{6}{|l|}{ Multivariate analysis } \\
\hline Gender & $p=0.85$ & $p=0.072$ & $p=0.19$ & $p=0.57$ & $p=0.20$ \\
\hline Education & $p=0.38$ & $p=0.70$ & $p=0.11$ & $p=0.11$ & $p=0.12$ \\
\hline Type of operation & $p=0.40$ & $p=0.12$ & $p=0.53$ & $p=0.84$ & $p=0.28$ \\
\hline Age & $p=0.018$ & $p=0.11$ & $p=0.13$ & $p=0.43$ & $p=0.021$ \\
\hline
\end{tabular}

Binary questions are summarized as proportions and scores as averages

CI confidence interval

${ }^{\text {a }}$ Possible values for this score ranged from 0 to 4 
Table 5 Analysis of the score postoperative decision making (score 2) and the binary questions involved

\begin{tabular}{|c|c|c|c|c|c|c|}
\hline & Q5 & Q6 & Q7 & Q8 & Q9 & Score "decision" \\
\hline Sample size & $n=253$ & $n=253$ & $n=252$ & $n=253$ & $n=252$ & $n=251$ \\
\hline Results, \% & 63.6 & 61.3 & 88.9 & 10.7 & 59.9 & 4.07 \\
\hline$(95 \% \mathrm{CI})$ & $(57.5 \%-69.3 \%)$ & $(55.1 \%-67.1 \%)$ & $(84.4 \%-92.2 \%)$ & $(7.4 \%-15.1 \%)$ & $(53.8 \%-65.8 \%)$ & $(3.86-4.27)$ \\
\hline \multicolumn{7}{|l|}{ Univariate analysis } \\
\hline Gender & $p=0.017$ & $p=1.00$ & $p=0.74$ & $p=0.18$ & $p=0.76$ & $p=0.19$ \\
\hline Education & $p=0.25$ & $p=0.057$ & $p=0.29$ & $p=0.18$ & $p=0.51$ & $p=0.015$ \\
\hline Type of operation & $p=0.072$ & $p=0.13$ & $p=0.43$ & $p=0.061$ & $p=0.52$ & $p=0.064$ \\
\hline Age & $p=0.001$ & $p=0.008$ & $p=0.22$ & $p=0.92$ & $p=0.066$ & $p=0.003$ \\
\hline \multicolumn{7}{|l|}{ Multivariate analysis } \\
\hline Gender & $p=0.041$ & $p=0.23$ & $p=0.93$ & $p=0.022$ & $p=0.89$ & $p=0.70$ \\
\hline Education & $p=0.60$ & $p=0.12$ & $p=0.72$ & $p=0.10$ & $p=0.52$ & $p=0.13$ \\
\hline Type of operation & $p=0.20$ & $p=0.11$ & $p=0.43$ & $p=0.037$ & $p=0.48$ & $p=0.17$ \\
\hline Age & $p=0.006$ & $p=0.001$ & $p=0.15$ & $p=0.45$ & $p=0.036$ & $p=0.002$ \\
\hline
\end{tabular}

Binary questions are summarized as proportions and scores as averages

${ }^{\text {a }}$ Possible values for this score ranged from 0 to 7

patients with a minor operation and a major oncological operation, respectively), but overall the type of operation was not significant ( $p=0.064$ and 0.17 in the univariate and multivariate analysis, respectively).

\section{Family}

Table 6 shows the results from questions on the role of the patient's family in medical decision making as answered by the patient. Thus, as long as a patient is conscious and able to participate, only $38.3 \%$ would like the family to be involved in the medical decision concerning reoperation or a further ICU stay (Q10), but $73.9 \%$ expressed this wish if the patient is unable to communicate (Q11). There was a tendency $(p=0.052)$ for women to favor consideration of the family's opinion even if they are still conscious. If the patient is conscious, only $29.0 \%$ of all patients would choose to include the family in the decision about whether resuscitation should be performed after a cardiac arrest (Q12); but this percentage rose to $57.4 \%$ if the patient is unconscious (Q13). Interestingly, up to $64.5 \%$ of respondents considered it as important that the treating physicians be involved in the decision making in case of a cardiac arrest.

In the score "family," summing up the four questions (score 3), men had significantly less desire to get the family involved than women (average score 1.81 vs. 2.17; $p=0.034$ ), the same being true for older patients compared to younger ones (on average -0.11 points every 10 years; $p=0.048$ ). These tendencies could be confirmed in the multivariate analysis, although they were no longer significant ( $p=0.20$ and $p=0.12$, respectively).

\section{Discussion}

The present study was performed to evaluate surgical patients' preferences for obtaining perioperative information and participating in decision making concerning serious potential complications, unexpected admission to an intensive care unit, cardiac arrest, and resuscitation or death prior to abdominal surgery. The role of gender, age, level of education, and type of operation were assessed as most relevant factors. Most patients were in favor of receiving detailed information about the planned operation and the postoperative course (e.g., ICU stay). As long as patients are conscious and communication is preserved, they desire to be involved in all decision making, especially where important decisions must be made (e.g., reoperation, re-transfer to ICU, resuscitation). Family members themselves become important if patients are unable to decide for themselves. Elderly patients generally are less demanding of information, and it seems that they rely more on their physicians in the decision-making process. These results corroborate the ones drawn from the literature reviewed. As reported in other studies in the literature, young female patients tend to seek more information than older male patients [20-22].

With regard to level of educational attainment, we found that patients with low or superior education had a tendency to seek less information than patients with an average educational level. From the literature, it appears that patients with a higher educational attainment are more likely to seek greater and more accurate information [23]. A possible explanation for our results could be that patients with a low education have less interest and comprehension of all the details and patients with a high educational level 
Table 6 Analysis the score family (score 3) and the binary questions involved

\begin{tabular}{|c|c|c|c|c|c|}
\hline & Q10 & Q11 & Q12 & Q13 & Score $3^{\mathrm{a}}$ \\
\hline Sample size & $n=253$ & $n=253$ & $n=252$ & $n=251$ & $n=250$ \\
\hline Results (\%) & $38.3 \%$ & $73.9 \%$ & $29.0 \%$ & $57.4 \%$ & 1.98 \\
\hline$(95 \% \mathrm{CI})$ & $(32.6 \%-44.5 \%)$ & $(68.2 \%-78.9 \%)$ & $(23.7 \%-34.9 \%)$ & $(51.2 \%-63.3 \%)$ & $(1.81-2.15)$ \\
\hline \multicolumn{6}{|l|}{ Univariate analysis } \\
\hline Gender & $p=0.052$ & $p=0.61$ & $p=0.015$ & $p=0.50$ & $p=0.034$ \\
\hline Education & $p=0.19$ & $p=0.23$ & $p=0.79$ & $p=0.96$ & $p=0.37$ \\
\hline Type of operation & $p=0.14$ & $p=0.37$ & $p=0.16$ & $p=0.21$ & $p=0.25$ \\
\hline Age & $p=0.24$ & $p=0.28$ & $p=0.21$ & $p=0.035$ & $p=0.048$ \\
\hline \multicolumn{6}{|l|}{ Multivariate analysis } \\
\hline Gender & $p=0.18$ & $p=0.96$ & $p=0.038$ & $p=0.75$ & $p=0.20$ \\
\hline Education & $p=0.44$ & $p=0.24$ & $p=0.94$ & $p=0.96$ & $p=0.74$ \\
\hline Type of operation & $p=0.26$ & $p=0.28$ & $p=0.32$ & $p=0.25$ & $p=0.46$ \\
\hline Age & $p=0.70$ & $p=0.10$ & $p=0.54$ & $p=0.074$ & $p=0.12$ \\
\hline
\end{tabular}

Binary questions are summarized as proportions and scores as averages

${ }^{\text {a }}$ Possible values for this score ranged from 0 to 4

are able to find information for themselves and have a good understanding on their own.

Previous research has focused primarily on understanding patients' needs during diagnosis and treatment of cancer or chronic illness, whereas the focus of the present study was solely on patients undergoing GI surgery, and did not take into account their diagnosis and prognosis.

Successful coping may be impaired during the perioperative phase because most patients are not accustomed to being exposed to difficult situations where they are confronted with potentially severe complications, resuscitation, or even risk of death. To represent the broad variety of patients at its best, we investigated not only elderly morbid patients suffering from metastatic cancer requiring a major surgery but also young healthy patients suffering from uncomplicated disease, e.g., cholecystolithiasis requiring a laparoscopic cholecystectomy. We are well aware that this study represents only a snapshot of patients' interests, as it is known from trials using a longitudinal study design that information needs of cancer patients may change throughout the clinical course of cancer [18, 24-28].

Accepting patients as autonomous individuals, and hence as partners with their physicians, is gaining ground $[2,3,10]$. In recent years, for example, the concept of "shared decision making" has been studied in general practice for chronic medical conditions such as diabetes mellitus [11, 12], but also in oncological patient groups, e.g., lung, prostate, colorectal, and breast cancer [17-21]. Patients have to sign an informed consent document prior to surgery in almost every country in the world, but this often represents a legal requirement [29, 30]. Signing an informed consent form does not necessarily mean that patients are well informed and have been involved in the decision-making process. The patient's signature only indicates agreement to undergo the planned surgical intervention. But effective shared decision making requires information that must be presented in an informative manner by the patient's physicians $[5-8,15]$. As a consequence, this study specifically aimed to shed light on what is meant by "adequate" information for surgical patients in different clinical situations, and their preferences regarding involvement in difficult decision making. Nevertheless, this study did not assess the extent to which patients have understood the information and its consequences for their disease. This is a significant element of providing adequate information, as several studies have shown that there are large areas of misunderstanding [31, 32]. Furthermore, this study did not investigate the various tools that can be used for providing patient information, e.g., audio tapes, videos, letters, oral information, or drawings [33-36]. Also, it could be considered an important shortcoming of this study that we did not use a previously described and validated questionnaire. Because there was no suitable questionnaire for this particular clinical situation, we developed a simple and easily understood questionnaire. Also of note, a recent review revealed that in almost $50 \%$ of published series, the data collection method was original, and in only $22 \%$ of studies has it been based on a pre-existing questionnaire (the other $27 \%$ of studies used interviews and other methods to collect patient information) [17].

\section{Information}

From the physician's point of view, providing more information aims, on the one hand, to increase patients' understanding in order to get better compliance and 
adherence to planned treatments, and on the other hand to reduce patients' anxiety [37-39]. The hope is that, subsequently, fewer complications, a shorter hospital stay, and, ultimately, optimized use of health care resources could eventually be achieved. A rather "soft" but nevertheless beneficial effect for patients is that they maintain a sense of control over their disease and its treatment. There is a widely held belief that more information can add more harm by increasing patients' anxiety, but very few data confirm this speculation. Patients receiving upfront the diagnosis of a malignant disease, or even worse, a metastatic malignant disease, may be overwhelmed by anxiety. They may temporarily be unable to sustain attention for detailed information and to participate in difficult decision making.

Our study confirmed that the majority of patients are interested in getting specific preoperative information on the diagnosis, the planned surgical procedure, and the most frequent complications $(73,75$, and $76 \%$, respectively). This need was not influenced by gender, level of education, or type of operation. Of note, elderly patients were significantly less interested in receiving extensive information. It is possible that these patients have cognitive impairments that limit their capacity to understand complex explanations; moreover, traditionally, preceding generations are used to trusting their doctors. Patients were very eager to be informed about a possible ICU stay, since they probably interpreted it as a sign of severity of their disease and the planned surgery. At a first glance, it seems to be somewhat contradictory that only $31 \%$ of all patients wanted to be informed about all possible complications. Rather, it indicates that patients' receptiveness is not unrestricted. As a consequence, information has to be easily comprehensible, and careful selection is mandatory. Likewise, if the intervention is judged to be minor, patients may assume that also the risks are limited and very detailed information is not needed. Cancer patients are generally well aware of the fact that their disease may be potentially life threatening, and they are already better informed or are ready to take larger risks, including major surgery.

Oral information provided in a personal conversation between patient and doctor may be complemented by written information containing text and drawings. The positive effect of combining different modalities in providing information has been shown in a Cochrane database review of information given to patients being discharged from hospital and in some studies for information given before a therapeutic modality [32, 34-36].

By summarizing the different aspects of patient information into a score, we found that elderly patients were significantly less demanding. In the literature [22, 23], similar results have been reported, and we found several possible explanations: as already mentioned in the preceding discussion, elderly patients traditionally trust and rely on their physicians because they accept them as the specialists responsible for their patients' care. Second, they may feel less competent to participate in discussions, because of impaired cognitive functions and hearing. Finally, some elderly patients, especially those with chronic and long-existing diseases, may also have already made their minds up about serious decisions-e.g., to limit medical efforts in case of a life-threatening complication.

\section{Decision making}

Our study dedicated to surgical patients shows that patients strongly wish to be included in decision making during ongoing treatment [3, 4]. This aspect of their health care becomes particularly obvious if decisions have to be taken in case of severe complications. From the patient's point of view, the treating physicians should initiate discussions preparing decisions, and pre-emptive decision making is preferred, especially for cancer patients. These results can be interpreted as demonstrating that control of their disease management is of utmost importance for many patients, and they are interested in participating in the decisions as long as they are conscious. For elderly patients, who generally trust their physicians to make correct decisions, the motivation is likely the same.

Besides the above-mentioned rational reasons, patient's decision making is often governed by non-medical considerations. Fear of losing independence and requiring permanent external support and help, lack of a secondary caregiver for a spouse, and even financial issues are factors that play an important role but often go unnoticed by the treating physicians. A further issue that is underestimated is the role of a patient's level of education. To be able to understand modern, often complex treatment regimens and its related complications, some intellectual capacities and knowledge are important prerequisites. Decision making is therefore potentially easier for patients with a higher level of education, also because they are able get information from other sources. In contrast, patients with a low level of education may be more dependent on the information provided by their physicians. To recognize these individual patient characteristics is a striking medical skill.

\section{Family}

Concerning the involvement of the patient's family, interestingly, it was more limited as generally admitted. There was a clear difference between a time when patients were still conscious and thus able to decide themselves and when patients could no longer participate in decision making. Only in the latter case was the family assigned to play an important role. These findings are similar to those reported in the 
literature. For example, Puchalski et al. [40] determined that patients would want their family members and physicians to make resuscitation decisions for them in case of loss of decision making capacity. As a consequence, physicians are obliged to privilege the patient for any decision as long as it is possible, whereas the family is of less importance. It can even be speculated that some patients prefer that physicians take their decisions without considering the family's point of view. Also of note, men and elderly patients were less interested in involving their families.

\section{Limitations of the study}

As noted earlier, the main limitation of the present study is the use of a non-validated questionnaire. Indeed, for this sensitive topic of patient-to-doctor relationship, several studies have been published without a validated questionnaire. Despite a careful review of the literature, we could not identify any suitable questionnaire covering the specific requirements of this study. To deal with this lack, a psychiatrist specialized in doctor-to-patient relationship helped us develop the questionnaire and choose the questions, inspired by the literature as much as possible [17-19].

Psychological profile as well as geographical origin or religious belief may have an influence on results, but their implication is difficult or even impossible to establish in a single outpatient surgical consultation [41].

\section{Conclusions}

This is, to our knowledge, the first study concerning information needs of patients undergoing GI surgery regardless of the diagnosis and prognosis concerning perioperative complications, risk of death, or need for resuscitation. The vast majority of surgical patients clearly want to get adequate preoperative information about their disease and the planned treatment. They also consider it crucial to be involved in any kind of decision making. For most patients, the family's role is limited to support of the treating physicians if the patient is unable to participate in decision making. Surgeons should avoid predicting their patients' preferences and start providing patients with a climate of "open communication" that allows the patient to achieve the desired level of participation during decision making. A simple screening during the pre-operative consultation regarding the patient's role preference can be beneficial and promote cooperation between the clinician and the patient. Demographic changes that lead to an ongoing increase in the number of elderly patients in treatment, and increased worldwide migration as well as more complex treatment modalities warrant regular adaptation of physicians' policies regarding patient information and patient participation in decision making.

\section{References}

1. Little P, Everitt H, Williamson I et al (2001) Preferences of patients for patient centred approach to consultation in primary care: observational study. BMJ 322:468-472

2. Mulley A (2009) Inconvenient truth about supplier induced demand and unwarranted variation in medical practice. BMJ 339:b4073

3. Edwards A, Elwyn G (2003) Shared decision-making. Achieving evidence-based patient choice. Patient Educ Couns 50:229-230

4. Hotta K, Kiura K, Takigawa N et al (2010) Desire for information and involvement in treatment decisions. $\mathrm{J}$ Thorac Oncol 5: $1668-1672$

5. Laine C, Davidoff F (1996) Patient-centered medicine: a professional evolution. JAMA 275:152-156

6. Deber RB, Kraetschmer N, Irvien J (1996) What role do patients wish to play in treatment decision-making? Arch Intern Med 156:1414-1420

7. Stewart MA (1995) Effective physician-patient communication and health outcomes: a review. Can Med Assoc J 152:1423-1433

8. Mead N, Bower P (2002) Patient-centred consultations and outcomes in primary care: a review of the literature. Patient Educ Couns 48:51-61

9. Mazur DJ, Hickam DH, Mazur MD (2005) The role of doctor's opinion in shared decision-making: what does shared decisionmaking really mean when considering invasive medical procedures? Health Expect 8:97-102

10. O'Connor A, Bennett C, Stacey D et al. (2009) Decision aids for people facing health treatment on screening decisions. Cochrane Database Syst Rev 3:CD001431

11. Greenfield S, Kaplan S, Ware JE (1988) Patients' participation in medical care: effects on blood sugar and quality of life in diabetes. J Gen Intern Med 3:448-457

12. Kaplan SH, Greenfield S, Ware JE (1989) Assessing the effects of physician-patient interactions on the outcomes of chronic disease. Med Care 27(supp 1):110-127

13. Fallowfield LJ, Hall A, Maguire GP et al (1989) Does choice of treatment affect psychological morbidity in early breast cancer? A three-year prospective study. Br J Surg 76:641

14. Kinmonth AL, Woodcock A, Griffin S et al (1998) Randomised controlled trial of patient centred care of diabetes in general practice: impact on current wellbeing and future disease risk. The Diabetes Care from Diagnosis Research Team. BMJ 317:1202-1208

15. Elwyn G, Edwards A, Kinnersley P et al (2000) Shared decision making and the concept of equipoise: the competences of involving patients in healthcare choices. Br J Gen Pract 50: 892-899

16. Langewitz W, Nübling M, Weber H (2006) Hospital patients' preferences for involvement in decision-making. A questionnaire survey of 1040 patients from a Swiss university hospital. Swiss Med Wkly 136:59-64

17. Davison BJ, Parker PA, Goldenberg SL (2004) Patients' preferences for communicating a prostate cancer diagnosis and participating in medical decision-making. BJU Int 93:47-51

18. Beaver K, Booth K (2007) Information needs and decisionmaking preferences: comparing findings for gynaecological, breast and colorectal cancer. Eur J Oncol Nurs 11:409-416

19. Bilodeau BA, Degner LF (1996) Information needs, sources of information, and decisional roles in women with breast cancer. Oncol Nurs Forum 23:691-696 
20. Degner LF, Kristjanson LJ, Bowman D et al (1997) Information needs and decisional preferences in women with breast cancer. JAMA 277:1485-1492

21. Bruera E, Willey JS, Palmer JL et al (2002) Treatment decisions for breast carcinoma: patient preferences and physician perceptions. Cancer 94:2076-2080

22. Davison BJ, Breckon E (2012) Factors influencing treatment decision making and information preferences of prostate cancer patients on active surveillance. Patient Educ Couns 87:369-374

23. Matsuyama RK, Wilson-Genderson M, Kuhn L et al (2011) Education level, not health literacy, associated with information needs for patients with cancer. Patient Educ Couns 85:e229-e236

24. Davidson JR, Brundage MD, Feldman-Stewart D (1999) Lung cancer treatment decisions: patients' desires for participation and information. Psychooncology 8:511-520

25. Friis LS, Elverdam B, Schmidt KG (2003) The patient's perspective: a qualitative study of acute myeloid leukaemia patients' need for information and their information-seeking behavior. Support Care Cancer 11:162-170

26. Carlsson ME, Strang PM (1998) How patients with gynecological cancer experience the information process. J Psychosom Obstet Gynaecol 19:192-201

27. Mills ME, Sullivan K (2000) Patients with operable oesophageal cancer: their experience of information-giving in a regional thoracic unit. J Clin Nurs 9:236-246

28. Sahay TB, Gray RE, Fitch M (2000) A qualitative study of patient perspectives on colorectal cancer. Cancer Pract 8:38-44

29. Mallardi V (2005) The origin of informed consent. Acta Otorhinolaryngol Ital 25:312-327

30. Salako SE (2011) Informed consent under the European Convention on Biomedicine and the UNESCO Declaration on Bioethics. Med Law 30:101-113

31. Sahin N, Oztörk A, Ozkan Y et al (2010) What do patients recall from informed consent given before orthopedic surgery? Acta Orthop Traumatol Turc 44:469-475
32. Ghulam AT, Kessler M, Bachmann LM et al (2006) Patients' satisfaction with the preoperative informed consent procedure: a multicenter questionnaire survey in Switzerland. Mayo Clin Proc $81: 307-312$

33. Kušec $S$, Orešković $S$, Škegro $M$ et al (2006) Improving comprehension of informed consent. Patient Educ Couns 60:294-300

34. Johnson A, Sandford J, Tyndall J (2003) Written and verbal information versus verbal information only for patients being discharged from acute hospital settings to home. Cochrane Database Syst Rev 4:CD003716

35. Gangol R, Maharjan D (2010) Information leaflet as an adjunct to verbal counseling in obtaining informed consent. J Nepal Med Assoc 49:117-120

36. Felley C, Perneger TV, Goulet I et al (2008) Combined written and oral information prior to gastrointestinal endoscopy compared with oral information alone: a randomized trial. BMC Gastroenterol 8:22

37. Astley CM, Chew DP, Aylward PE et al (2008) A randomised study of three different informational AIDS prior to coronary angiography, measuring patient recall, satisfaction and anxiety. Heart Lung Circ 17:25-32

38. Hughes S (2002) The effects of giving patients pre-operative information. Nurs Stand 16:33-37

39. Scott A (2004) Managing anxiety in ICU patients: the role of preoperative information provision. Nurs Crit Care 9:72-79

40. Puchalski CM, Zhong Z, Jacobs MM et al (2000) Patients who want their family and physician to make resuscitation decisions for them: observations from SUPPORT and HELP. Study to Understand Prognoses and Preferences for Outcomes and Risks of Treatment. Hospitalized Elderly Longitudinal Project. J Am Geriatr Soc 48(5 Suppl):84-90

41. Albain KS, Green SR, Lichter AS et al (1996) Influence of patient characteristics, socioeconomic factors, geography, and systemic risk on the use of breast-spearing treatment in women enrolled in adjuvant breast cancer studies: an analysis of two intergroup trials. J Clin Oncol 14:3009-3017 